\title{
Triggered Surface Slips in the Salton Trough Associated with the 1999 Hector Mine, California, Earthquake
}

\author{
by Michael J. Rymer, John Boatwright, Linda C. Seekins, J. Douglas Yule, and Jing Liu
}

\begin{abstract}
Surface fracturing occurred along the southern San Andreas, Superstition Hills, and Imperial faults in association with the 16 October $1999\left(M_{\mathrm{w}} 7.1\right)$ Hector Mine earthquake, making this at least the eighth time in the past 31 years that a regional earthquake has triggered slip along faults in the Salton Trough. Fractures associated with the event formed discontinuous breaks over a 39-km-long stretch of the San Andreas fault, from the Mecca Hills southeastward to Salt Creek and Durmid Hill, a distance from the epicenter of 107 to $139 \mathrm{~km}$. Sense of slip was right lateral; only locally was there a minor $(\sim 1 \mathrm{~mm})$ vertical component of slip. Dextral slip ranged from 1 to $13 \mathrm{~mm}$. Maximum slip values in 1999 and earlier triggered slips are most common in the central Mecca Hills. Field evidence indicates a transient opening as the Hector Mine seismic waves passed the southern San Andreas fault. Comparison of nearby strong-motion records indicates several periods of relative opening with passage of the Hector Mine seismic wave-a similar process may have contributed to the field evidence of a transient opening.

Slip on the Superstition Hills fault extended at least $9 \mathrm{~km}$, at a distance from the Hector Mine epicenter of about 188 to $196 \mathrm{~km}$. This length of slip is a minimum value, because we saw fresh surface breakage extending farther northwest than our measurement sites. Sense of slip was right lateral; locally there was a minor $(\sim 1$ $\mathrm{mm}$ ) vertical component of slip. Dextral slip ranged from 1 to $18 \mathrm{~mm}$, with the largest amounts found distributed (or skewed) away from the Hector Mine earthquake source. Slip triggered on the Superstition Hills fault commonly is skewed away from the earthquake source, most notably in 1968, 1979, and 1999.

Surface slip on the Imperial fault and within the Imperial Valley extended about $22 \mathrm{~km}$, representing a distance from the Hector Mine epicenter of about 204 to 226 $\mathrm{km}$. Sense of slip dominantly was right lateral; the right-lateral component of slip ranged from 1 to $19 \mathrm{~mm}$. Locally there was a minor $(\sim 1-2 \mathrm{~mm})$ vertical component of slip; larger proportions of vertical slip (up to $10 \mathrm{~mm}$ ) occurred in Mesquite basin, where scarps indicate long-term oblique-slip motion for this part of the Imperial fault. Slip triggered on the Imperial fault appears randomly distributed relative to location along the fault and source direction. Multiple surface slips, both primary and triggered slip, indicate that slip repeatedly is small at locations of structural complexity.
\end{abstract}

\section{Introduction}

The $M_{\mathrm{w}}$ 7.1 Hector Mine earthquake of 16 October 1999 in the Mojave Desert, southern California, was associated with primary tectonic rupture on many faults in the epicentral area (Treiman et al., 2002; Fig. 1) and remotely triggered minor slip on many other faults in the Mojave Desert area at distances of about 30 to $40 \mathrm{~km}$ (Treiman et al., 2002). The Hector Mine earthquake also triggered surface slip on faults in the Salton Trough, from about 100 to $280 \mathrm{~km}$ to the south. The Hector Mine earthquake was only the most recent earthquake of many local or regional earthquakes within the past three decades to have triggered slip on faults in the Salton Trough.

Triggered surface breaks were documented in the Salton Trough following the 1968 Borrego Mountain earthquake (Allen et al., 1972), the 1979 Imperial Valley earthquake (Fuis, 1982; Sieh, 1982), the 1981 Westmorland earthquake (Sharp et al., 1986a), the 1986 North Palm Springs earthquake (Sharp et al., 1986b; Williams et al., 1988), the 1987 Superstition Hills earthquake (Hudnut and Clark, 1989; Sharp, 1989), and the 1992 Joshua Tree and Landers earth- 


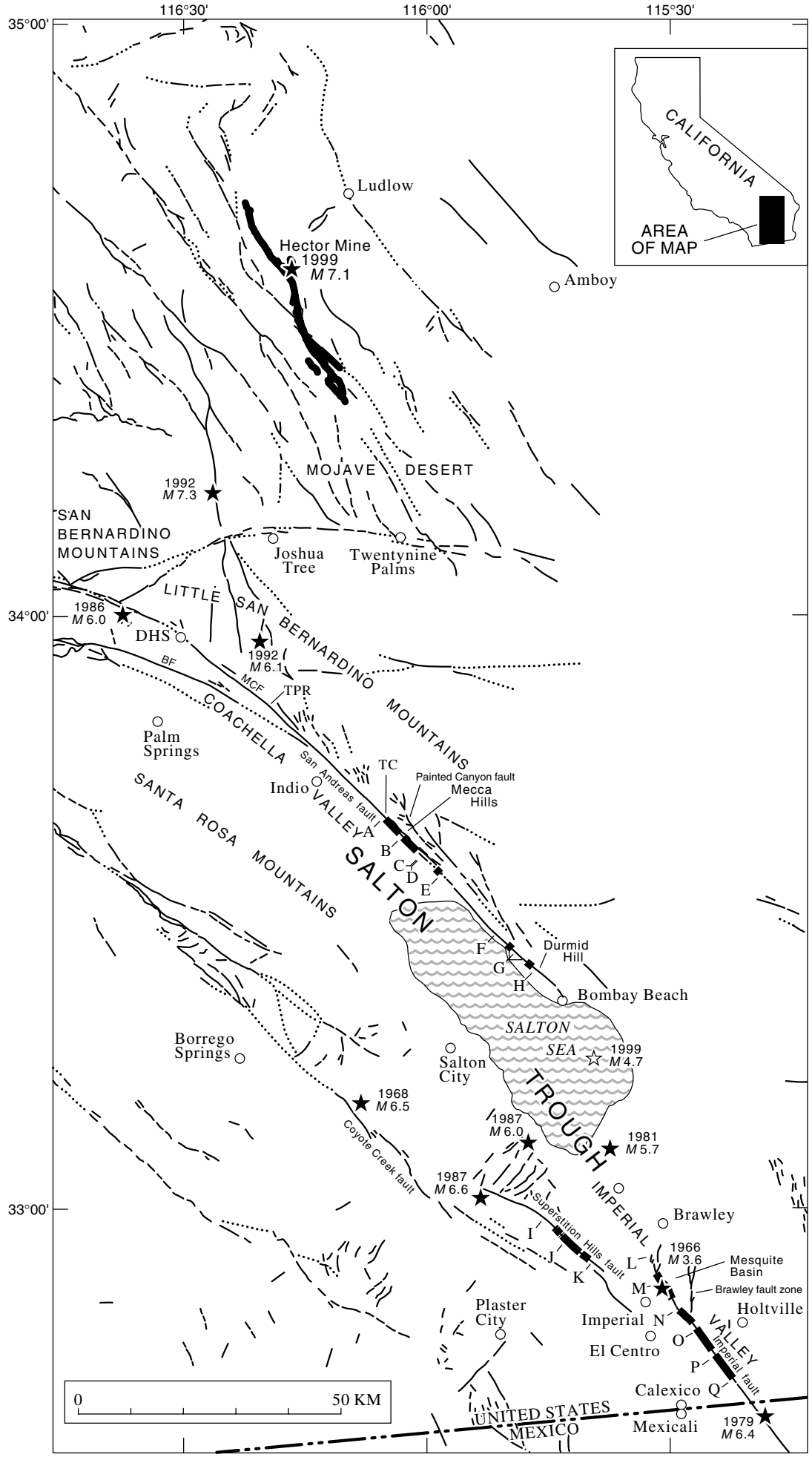

Figure 1. Index map showing Quaternary active faults in the greater Salton Trough and south-central Mojave Desert areas (modified from Jennings, 1994). Heavy line in Mojave Desert, 1999 Hector Mine surface faulting. Black bars in Salton Trough show generalized location of surface slip along San Andreas, Superstition Hills, and Imperial faults triggered by the Hector Mine earthquake. Large black star marks location of Hector Mine mainshock epicenter (labeled with magnitude 7.1). Small black stars with date and magnitude indicate epicenters of earlier earthquakes that also triggered slip on southern San Andreas, Superstition Hills, or Imperial faults. BF, Banning fault; DHS, Desert Hot Springs; MCF, Mission Creek fault; TC, mouth of Thermal Canyon; TPR, Thousand Palms Road. Letters $A$ to $H$ mark location of ends of strip maps of San Andreas fault shown in Fig. 2; letters $I$ to $K$ mark location of ends of strip maps of Superstition Hills fault shown in Fig. 5; letters $L$ to $Q$ mark location of ends of strip maps of Imperial fault shown in Fig. 6. quakes (Bodin et al., 1994; Rymer, 2000). Instrumental recordings of triggered slip, aseismic surface slip, and afterslip also were reported for events in the Salton Trough (Goulty et al., 1978; Cohn et al., 1982; Louie et al., 1985; Bilham, 1989; McGill et al., 1989).

Within the past three decades, triggered slip has been documented along the southernmost San Andreas fault in the southeastern Coachella Valley in four discrete earthquakes (Allen et al., 1972; Sieh, 1982; Williams et al., 1988; Rymer, 2000) and in many additional slip pulses determined by creepmeters and repeated surveys (e.g., Williams and Sieh, 1987; Williams et al., 1988; McGill et al., 1989), along 
with episodic dextral creep (Louie et al., 1985; Sieh and Williams, 1990). If such surface movement has occurred throughout the period since the last great earthquake, about 320 years ago (Sieh and Williams, 1990), then the net displacement could add up to tens of centimeters of displacement, representing a significant amount of shallow strain release.

This report describes the distribution and amount of triggered slip on the San Andreas, Superstition Hills, and Imperial faults within the Salton Trough and associated with the 1999 Hector Mine earthquake. Our tectonic interpretations are based on field measurements, as well as comparison with earlier triggered slips on the same faults and primary tectonic rupture on the latter two of these faults. A second component of this report compares triggered slip on the San Andreas fault and strong-motion records associated with the 1999 Hector Mine earthquake. Macroscopic features observed along the San Andreas fault in 1999 indicated a shortterm transient opening or propagating wrinklelike pulse of the fault during triggered-slip movement; comparison of strong-motion records on either side of the fault suggests the plausibility of this process. We also describe geologic evidence of an aseismic surface slip that developed along the San Andreas fault in the fall of 1997; this slip partially filled a gap in earlier-measured triggered slip and demonstrates the nature of slip on faults within the Salton Trough, if not elsewhere.

\section{San Andreas Fault}

Field checks for surface breakage along the San Andreas fault in the southeastern Coachella Valley began on the day of the Hector Mine earthquake. Two of us (J.L. and J.D.Y.) checked the San Andreas fault in the area of Salt Creek, Bat Caves Buttes, and Durmid Hill (Figs. 1, 2) on 16 and 17 October 1999. Field checks were made in the Indio Hills, Mecca Hills, Box Canyon, and Bombay Beach areas, along with many other localized checks, by M.J.R. on 1921 October 1999.

Discontinuous surface breaks formed along the San Andreas fault over a distance of about $39 \mathrm{~km}$ (Figs. 2, 3; Table 1), representing distances from the Hector Mine epicenter to the northwest and southeast endpoints of triggered slip of about 107 and $139 \mathrm{~km}$, respectively (Table 1). Breaks developed in two broad areas, the Mecca Hills and the Salt Creek-Durmid Hill area; a distance of almost $20 \mathrm{~km}$ separates these two broad areas. Areas where surface breaks formed lie in uplifted Pleistocene fine-grained lacustrine and fluvial deposits. See Bilham and Williams (1985) for discussion of structural relations to triggered slip occurrence and Rymer (2000) for discussion of distribution of triggered slip and local geologic materials.

Slip components were determined by measuring the displacement between matching irregularities in soil blocks or thin soil crusts along the local strike of the fault. We measured the slip vector, the azimuth of the slip, and the local strike of the fault; where present, the vertical component of slip and the direction of relative vertical displacement were also measured. Offset values were small, nowhere greater than $13 \mathrm{~mm}$ (Figs. 2, 3). Dextral slip greater than $6 \mathrm{~mm}$ apparently was confined to two areas in the Mecca Hills, between the mouth of Thermal Canyon to about $0.6 \mathrm{~km}$ southeast of Quarry Canyon and between Red Canyon and Painted Canyon (Fig. 2, panels $A-B$ and $B-C$ ).

\section{Transient Opening and Strong-Motion Records}

A feature that further reveals the nature of surface rupture was observed in association with the 1999 triggered slip along the San Andreas fault southeast of Quarry Canyon (Fig. 2, panel $A-B$ ). Figure 4 shows details of triggered slip at this site, where a thin soil surface was broken and offset along an en echelon fracture. Perspective drawings of the fractured soil surface (Fig. 4C and D) illustrate that slip at this site could not have been as a simple lateral slip parallel with the fault. Compare Figure $4 A-C$; simple linear motion of matching features $\mathrm{X}$ and $\mathrm{X}^{\prime}$ would have broken the thin soil chip $\left(\mathrm{X}^{\prime}\right)$. Rather, we believe that features shown in Figure 4 indicate a transient opening during right-lateral triggered slip. Such an opening would allow the delicate chips to be preserved; after the opening passed and lateral slip was completed, the opening closed as much as possible, given new fault-surface irregularities.

Brune et al. (1993) cited R. Sharpe [R. V. Sharp] for observations following the 1976 Guatemalan earthquake $\left(M_{\mathrm{s}}\right.$ 7.5) that had primary tectonic strike-slip displacement averaging approximately $95 \mathrm{~cm}$, and at least locally also had a minimum of 3 to $4 \mathrm{~cm}$ of motion perpendicular to the trace of the fault. This was evidenced by the preservation of smallscale jogs in the fault trace, which can only be explained if the opposite sides of the fault first moved apart, then moved in a strike-slip manner, then moved together again (Brune et al., 1993). Our observations on the San Andreas fault require similar processes of opening, strike-slip motion, and then closing, but as remotely triggered slip about $110 \mathrm{~km}$ from the causative earthquake.

To test our 1999 observations and inferences of a transient opening, we studied nearby strong-motion records from the Hector Mine earthquake. Figure 5 shows the locations of five strong-motion stations situated near the southern San Andreas fault and near the feature shown in Figure 4. These strong-motion stations lie at distances from the Hector Mine epicenter of about 90 to $150 \mathrm{~km}$. All of the stations are southwest of the San Andreas fault, except for station FRK; stations 542 and FRK bracket the San Andreas fault, lying within and outside of the Salton Trough, respectively, and are situated at about the same distance from the Hector Mine mainshock, $149 \mathrm{~km}$. A time-distance plot of strong motions from the Hector Mine earthquake shows the displacement at these strong-motion stations (Fig. 6). Figure 6 also overlays the displacement of stations 542 and FRK; taken together, these data suggest several periods of relative opening, 

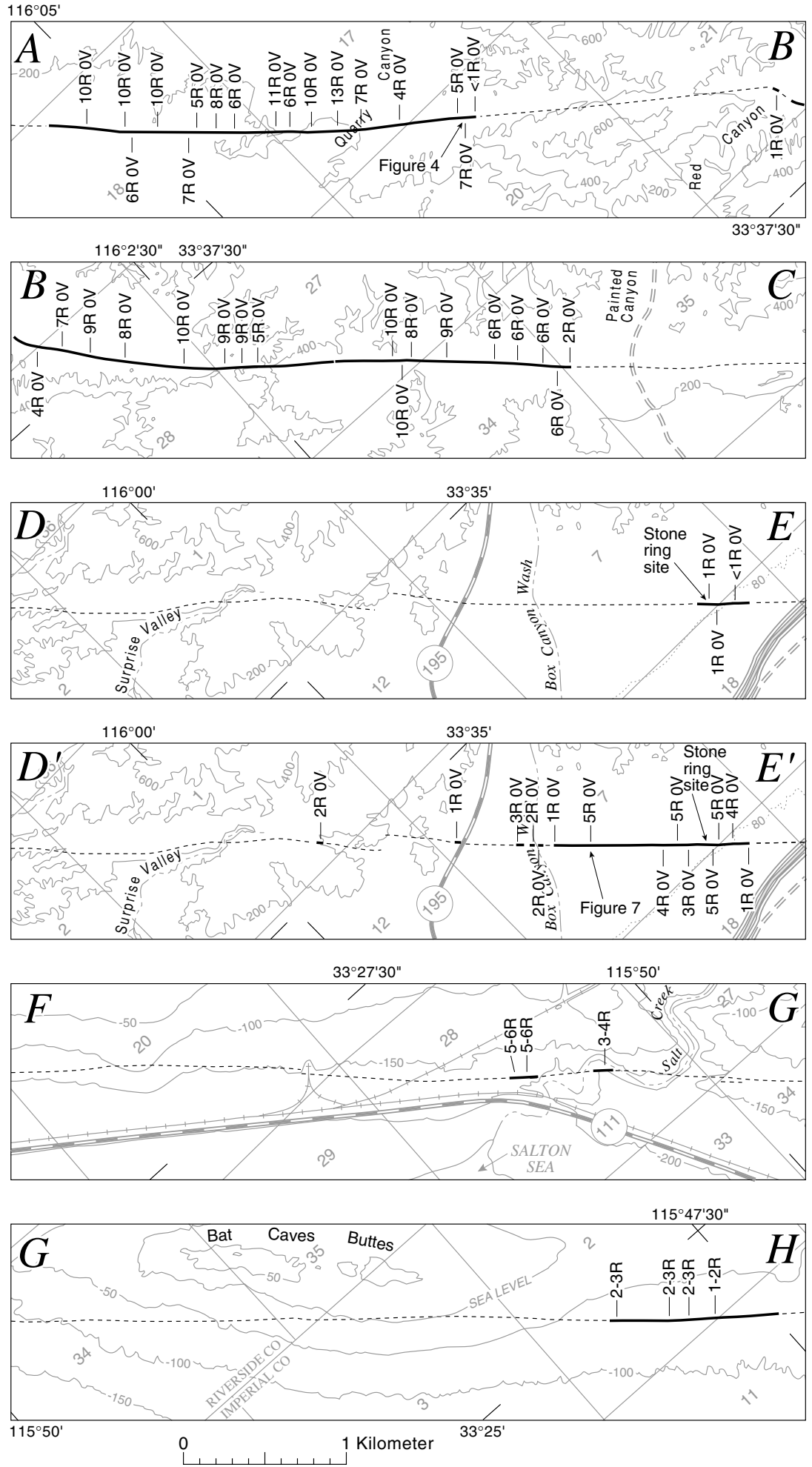

Figure 2. Strip maps from northwest to southeast along the southern San Andreas fault with location of surface fractures formed in association with 1999 Hector Mine earthquake. Dotted line, San Andreas fault; solid line, location of documented 1999 surface fractures. Slip values shown in millimeters for both rightlateral (R) and vertical (V) components. Vertical components of slip, where present, are indicated with either west (W) or east (E) side up. Map strips derived using selected contours from topographic maps; location of fault from Clark (1984); location of strips shown in Fig. 1. Strip map $D^{\prime}-E^{\prime}$ is plot of surface fractures formed during aseismic creep event in fall of 1997 (see text for details). shaded in dark gray. The largest relative openings, as much as $4 \mathrm{~cm}$, occurred between approximately 30 and $50 \mathrm{sec}$. Although records from stations 542 and FRK suggest that there may have been opening during the Hector Mine earthquake, no triggered surface slip was observed immediately nearby (the San Andreas fault at Bombay Beach and along the southeastern part of Durmid Hill was checked carefully three days after the earthquake). The closest stations to the triggered slip shown in Figure 4 are MEC and INO. We infer that relative openings similar to those shown in Figure 6 may have occurred across the San Andreas fault where triggered slip did form. 

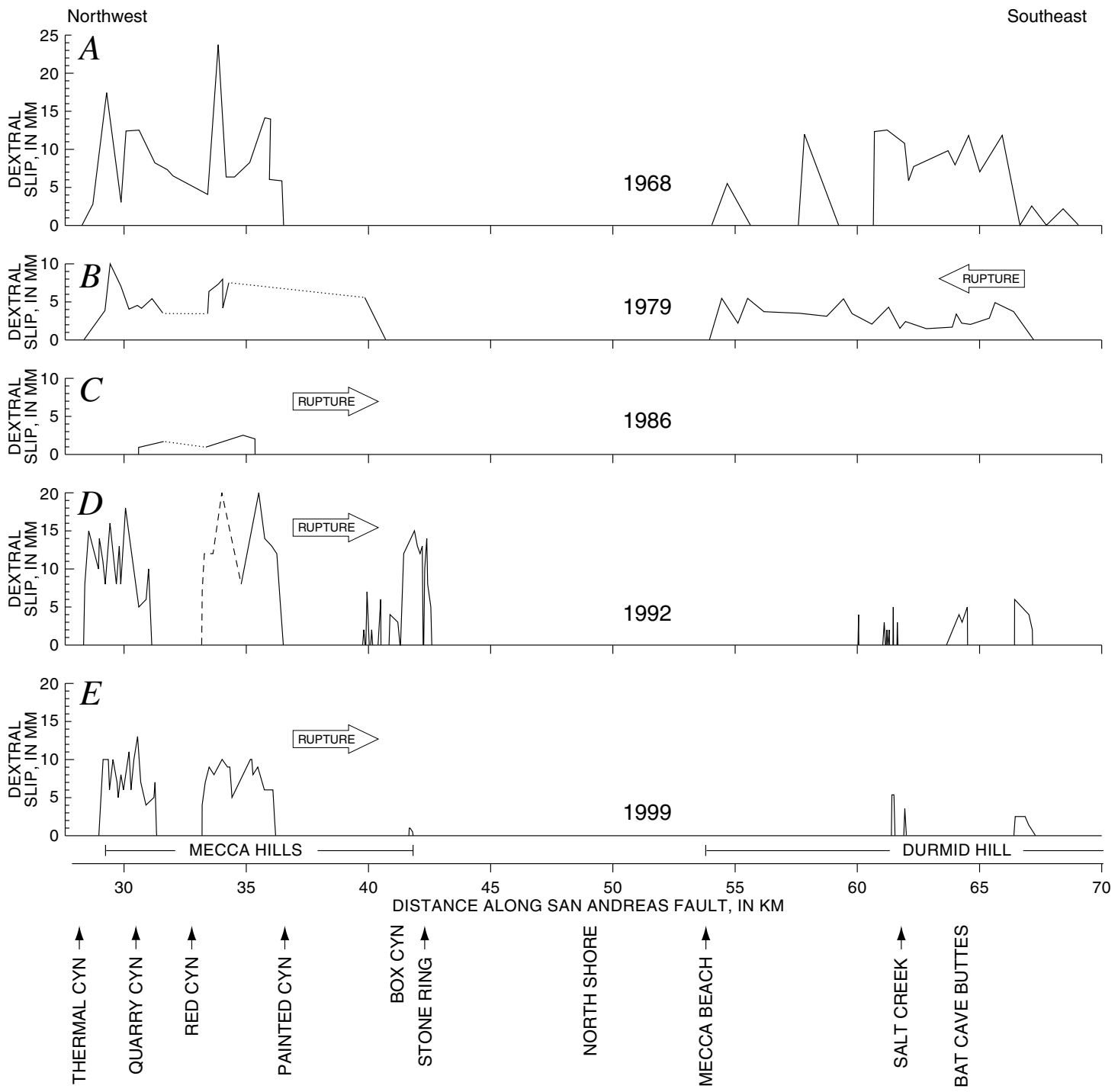

Figure 3. Right-lateral component of triggered slip as a function of distance along San Andreas fault. A, Triggered slip in 1968 (from Allen et al., 1972); B, triggered slip in 1979 (from Sieh, 1982); $C$, triggered slip in 1986 (from Williams et al., 1988) (slip in Indio Hills not shown); $D$, triggered slip in 1992 (from Rymer, 2000) (slip in Indio Hills not shown); $E$, triggered slip in 1999. Distance scale along fault is relative to intersection of Thousand Palms Road and the San Andreas fault (see Fig. 1). Wide horizontal arrow marks direction of rupture for individual earthquakes; seismic waves from the 1968 Borrego Mountain earthquake arrived approximately normal to the San Andreas fault and thus no rupture direction is shown for that event. Slip measured on creepmeters not included in these plots. Caltech measurement arrays and creepmeters, some of which are now inactive, located at: Red Canyon, North Shore, Mecca Beach, and Salt Creek (Louie et al., 1985; McGill et al., 1989).

\section{Aseismic Creep Event}

Here we briefly diverge from the 1999 Hector Mine triggered slip for a short description of aseismic slip that occurred about two years earlier along part of the same area of the southern San Andreas fault. We present this information to further describe the range of surface slip behavior in the region. In the fall of 1997, a localized strain event developed along the San Andreas fault in the Mecca Hills that resulted in discrete cracks with consistent right-lateral offset. Surface slip in this event was restricted to the Box Canyon area (Fig. 2, panel $D-E$ ), where triggered slip occurred in association with the 1992 Landers earthquake (Shifflett and Witbaard, 1996; Rymer, 2000) and later with the 1999 Hector Mine earthquake (this article).

Surface breakage along the San Andreas fault occurred some time between 25 September 1997 and 15 November 
Table 1

Characteristics of Triggered Slip along San Andreas, Superstition Hills, and Imperial Faults in the Salton Trough*

\begin{tabular}{|c|c|c|c|c|c|}
\hline $\begin{array}{l}\text { Year of } \\
\text { Event }\end{array}$ & $\begin{array}{l}\text { Magnitude } \\
\left(M_{\mathrm{w}}\right)\end{array}$ & $\begin{array}{l}\text { Approx. Azmuthal }{ }^{\dagger} \\
\text { Direction of Waves }\end{array}$ & $\begin{array}{l}\text { Extent of } \\
\text { Triggered Slip } \\
\text { along Fault } \\
(\mathrm{km})\end{array}$ & $\begin{array}{l}\text { Distance to Epicenter } \\
\qquad(\mathrm{km})\end{array}$ & $\begin{array}{c}\text { Maximum } \\
\text { Slip Value } \\
\quad(\mathrm{mm})\end{array}$ \\
\hline \multicolumn{6}{|c|}{ San Andreas Fault } \\
\hline 1968 & 6.5 & $005^{\circ}-053^{\circ}$ & 41 & $35-45$ & 24 \\
\hline 1979 & 6.4 & $328^{\circ}-333^{\circ}$ & 39 & $100-136$ & 10 \\
\hline 1981 & 5.6 & - & - & - & - \\
\hline 1986 & 6.0 & $125^{\circ}-131^{\circ}$ & $25 \S$ & $44-86$ & 9 \\
\hline 1987 & 6.6 & - $^{\|}$ & - & - & — \\
\hline 1992 & 7.3 & $146^{\circ}-152^{\circ}$ & $54^{\S}$ & 54-105 & 20 \\
\hline 1999 & 7.1 & $161^{\circ}-170^{\circ}$ & 38 & $107-139$ & 13 \\
\hline \multicolumn{6}{|c|}{ Superstition Hills Fault } \\
\hline 1968 & 6.5 & $125^{\circ}$ & 23 & $28-56$ & 25 \\
\hline 1979 & 6.4 & $309^{\circ}-312^{\circ}$ & 23 & $41-60$ & 22 \\
\hline 1981 & 5.6 & $200^{\circ}-252^{\circ}$ & 16 & $20-25$ & 14 \\
\hline 1986 & 6.0 & - & - & - & - \\
\hline 1987 & 6.6 & Causative fault & & & \\
\hline 1992 & 7.3 & $\sim 155^{\circ}$ & $\#$ & $\sim 145-165$ & 8 \\
\hline 1999 & 7.1 & $163^{\circ}-165^{\circ}$ & $9 * *$ & $188-196$ & 18 \\
\hline \multicolumn{6}{|c|}{ Imperial Fault } \\
\hline 1968 & 6.5 & $119^{\circ}-125^{\circ}$ & 22 & $63-83$ & 20 \\
\hline 1979 & 6.4 & Causative fault & & & \\
\hline 1981 & 5.6 & $154^{\circ}-160^{\circ}$ & 17 & $23-39$ & 8 \\
\hline 1986 & 6.0 & - & - & - & - \\
\hline 1992 & 7.3 & $-^{\dagger \dagger}$ & - & - & - \\
\hline 1999 & 7.1 & $158^{\circ}-160^{\circ}$ & 22 & $204-226^{+*}$ & 19 \\
\hline
\end{tabular}

*Each of these events also triggered slip on other faults or on other parts of the San Andreas fault zone (for details see reports on individual earthquakes).

"Measured from epicenter to endpoints of triggered slip.

${ }^{\ddagger}$ Measured from southeast and northwest endpoints of slip; each slip event is associated with discontinuous slip.

${ }^{\S}$ In Figure 3 we do not show location or amount of slip in the Indio Hills that occurred in 1986 (Williams et al., 1988) and 1992 (Rymer, 2000).

"McGill et al. (1989) instrumentally measured minor distributed slip, but no discrete surface fault slip occurred.

"Triggered slip along the Superstition Hills fault was not investigated following the 1992 Landers earthquake.

**Surface slip along the Superstition Hills fault in 1999 extended more than $9 \mathrm{~km}$, but was not mapped in detail any farther (see text for details).

${ }^{\top}$ R.V. Sharp (oral communication, 1992) stated there was no triggered slip on the Imperial fault associated with the 1992 Landers earthquake.

\#Instrumentally determined triggered slip also occurred on the Imperial fault in the Mexicali Valley, 275$280 \mathrm{~km}$ from the 1999 Hector Mine epicenter (Glowacka et al., 2002).

1997. The earlier date coincides with Hurricane Nora, which was associated with heavy precipitation and runoff. Precipitation was heavy enough to have reset the ground conditions and thus remove evidence of any earlier surface slip. The latter date is the timing of a South Coast Geological Society field trip to the San Andreas fault and subsequent coincidental observations of the new surface slip. Another participant on the field trip (G. R. Roquemore, Irvine Valley College) accompanied one of us (M.J.R.) and walked out parts of the surface breakage near the stone ring site (Fig. 2, panel $D-E$ ) of Shifflett and Witbaard (1996).

A dedicated search for surface breakage began three days later, extending from 18 to 21 November 1997, when M.J.R. walked out the new surface breaks near the mouth of Box Canyon in the Mecca Hills and walked out or checked other sites along the San Andreas fault that have slipped in the past. These searches extended about $50 \mathrm{~km}$, from Bombay Beach northwestward to the mouth of Thermal Canyon (Fig. 1). Surface breaks were mapped for a distance of only about $2.5 \mathrm{~km}$; greater continuity of slip and greater amounts of slip were located southeast of the main wash of Box Canyon (Fig. 2, $D^{\prime}-E^{\prime}$ ). The surface breaks occurred in the active alluvial wash of Box Canyon, in old alluvial deposits forming small hills, and in other, less active alluvial areas 

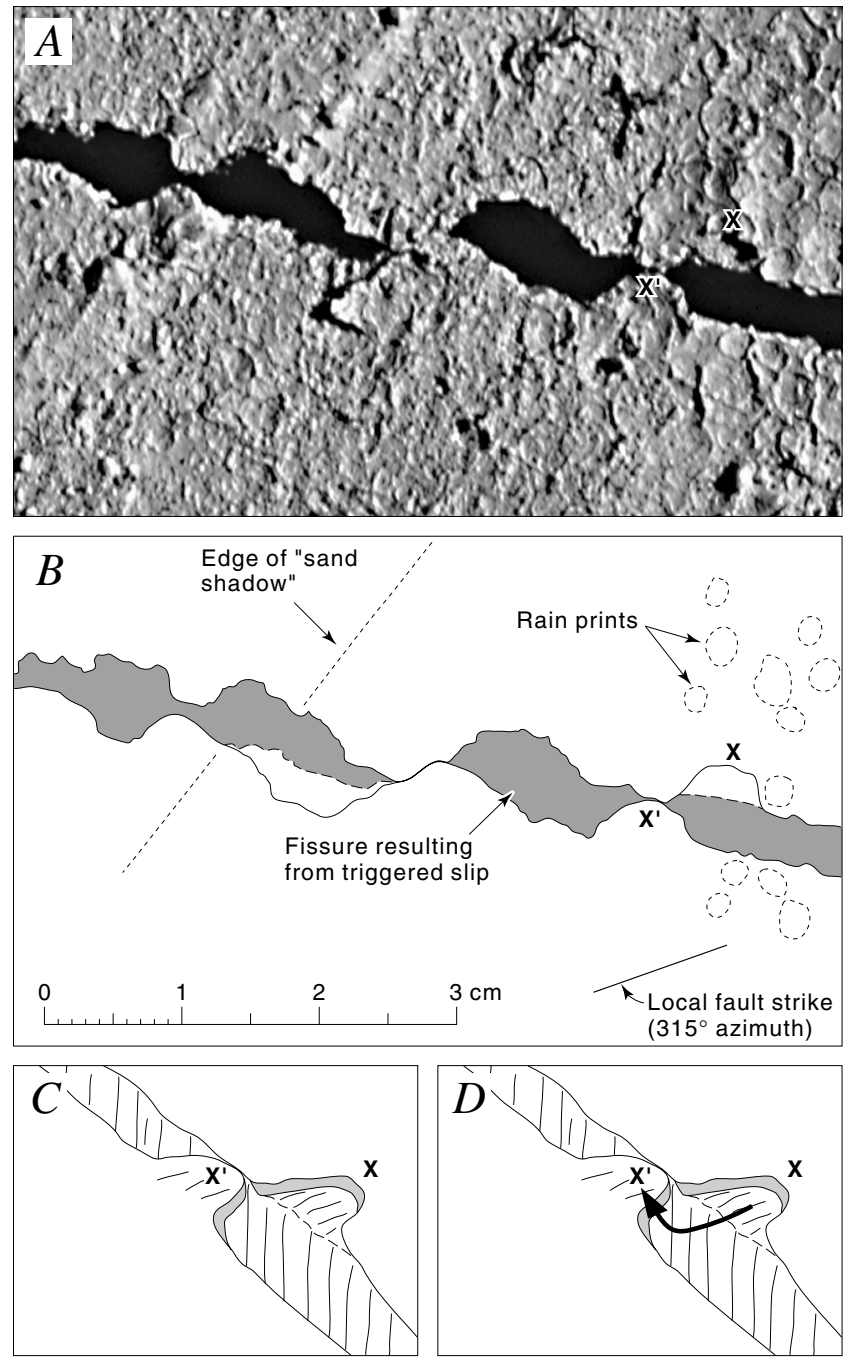

Figure 4. Triggered slip on San Andreas fault in modern wash tributary to Quarry Canyon, with $7 \mathrm{~mm}$ of right-lateral component of displacement and no vertical component. $A$, photograph of fracture and offset features; $\mathrm{X}$ and $\mathrm{X}^{\prime}$ are matches across fault. $B$, Line drawing of features shown in $A$. $C$, Schematic perspective drawing of features $X-X^{\prime}$. Feature $X^{\prime}$ is 1- to $11 / 2$-mm-thick tab of surface clay. $D$, Inferred relative motion of southwest $\left(\mathrm{X}^{\prime}\right)$ side of fault. Fracture must have opened at least length of tab $\mathrm{X}^{\prime}$ before right-lateral motion, otherwise tab would have chipped or broken. Photograph taken 21 October 1999.

north of the Coachella Canal; two short, isolated surface breaks occurred northwest of State Highway 195 (Fig. 2, D'$\left.E^{\prime}\right)$. Everywhere present, the surface slip formed left-stepping en echelon breaks with a right-lateral component of displacement. Figure 7 shows en echelon fractures in alluvium along the trace of the San Andreas fault, east of the main wash of Box Canyon. A right-lateral component of slip is readily apparent because of separation of matching features subparallel to the local trend of the fault.
Horizontal slip was greatest in Box Canyon, southeast of the main wash, and in small hills east of Box Canyon (Fig. 2, $D^{\prime}-E^{\prime}$ ). The right-lateral component of slip on the new breaks was small, from 1 to $5 \mathrm{~mm}$; no vertical component of slip was measured.

Movement on the southern San Andreas fault in the fall of 1997 apparently was aseismic. In the period of 25 September to 15 November 1997 there was no earthquake large enough to cause primary tectonic rupture. (During this period, a small cluster of $M \sim 2$ earthquakes formed northeast of the San Andreas fault in the northern Mecca Hills, approximately $10 \mathrm{~km}$ away; L. M. Jones, U.S. Geological Survey, oral commun., 1997.) Also, there were no local, regional, or global earthquakes of any significance during this period to trigger slip on the San Andreas fault.

The presence of aseismic surface slip events along the southern San Andreas fault, as described above, comes as little surprise. Louie et al. (1985) stated that for the 18-year period from 1967 to 1985 the San Andreas fault in the area had an average slip rate, excluding triggered slips, of about $1.5 \mathrm{~mm} / \mathrm{yr}$. Thus, one may expect creep events. The remote nature of the desert in the region makes for infrequent visits to the fault traces, and thus similar creep events may occur without being noticed. Of greater interest is the localization of slip near the mouth of Box Canyon, where triggered slip was not reported in 1968 (Allen et al., 1972) or 1979 (Sieh, 1982), but was noted in 1992 (Shifflett and Witbaard, 1996; Rymer, 2000). Also, there was additional slip, albeit small, in the same area associated with the 1999 Hector Mine earthquake, described above (Fig. 2, panels $D-E$ and $D^{\prime}-E^{\prime}$ ). Apparently, the area presently is in a decade-plus period of episodic slip. This observation, combined with the geodetic and creepmeter measurements and conclusions of Louie et al. (1985), suggests that creeping faults do not necessarily slip at a constant rate, but rather slip can occur in phases of a few years or longer, interspersed with periods of either no slip or decreased slip.

We were careful to take into account possible relations of the new surface fractures along the San Andreas fault and rainfall associated with Hurricane Nora. We still conclude that cracks formed near the mouth of Box Canyon in the fall of 1997 indeed are from aseismic slip, as opposed to a swelland-shrink process associated with moisture increase followed by desiccation. In this latter process, clays in fault gouge, or entrained clay-rich sediment in a fault, swell with increased moisture content during rainfall and runoff. In desert environments, as in the Coachella Valley and many other areas of southern California, shortly after rainfall the area returns to dry conditions wherein the clays shrink. Where a fault containing abundant clays is at or close to the surface, desiccation cracks then form along the fault. This phenomenon is most common in canyons or washes, where rainfall accumulates. For geologists looking for faults, the resulting desiccation cracks may aid in identification of fault location, but these same features may mislead an investigator into thinking there has been surface slip or that, somehow, the 


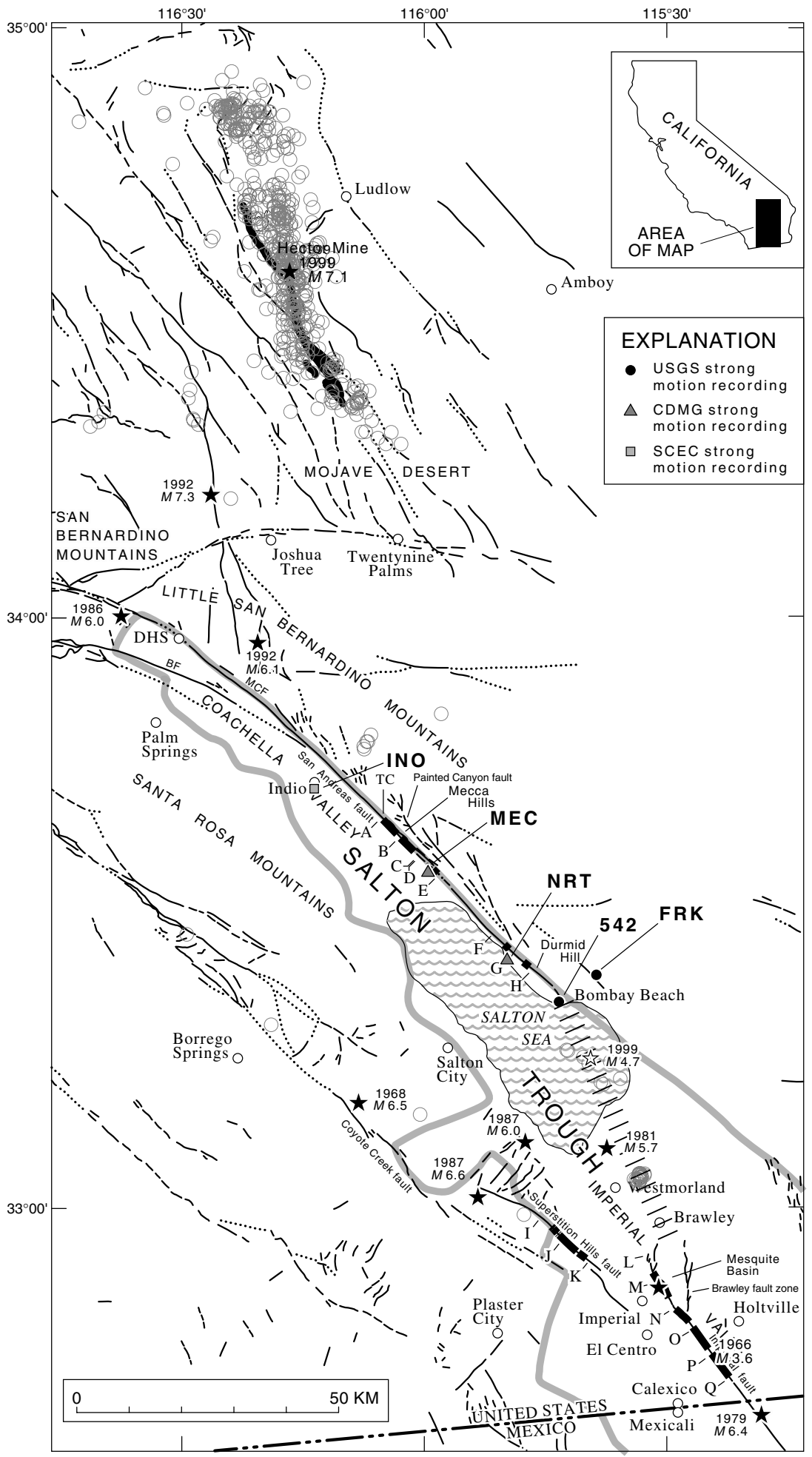

Figure 5. Map of Quaternary-active faults in the Salton Trough and south-central Mojave Desert areas (same area as Fig. 1). Map also shows inferred subsurface boundary of Salton Trough (heavy gray line), Brawley seismic zone (short diagonal lines between Imperial fault and San Andreas fault at Bombay Beach), and location of strong motion stations INO, MEC, NRT, FRK, and 542 near southern San Andreas fault (see description in text and Fig. 6). Boundary of Salton Trough from Saltus and Jachens (1995), for the Coachella Valley area, and Fuis et al. (1982), for the Imperial Valley area.

desiccation cracks are a measure of overall activity of the fault. For strike-slip faults in the San Andreas fault system, an easy way to discern surface-slip events from paleorainfall indicators is that surface slip will have a horizontal component of offset (with a consistent sense of slip), whereas with swell-and-shrink processes there is no horizontal offset, rather cracks with only opening across them. Figure 7 clearly shows a right-lateral component of slip associated with the 1997 observations along the San Andreas fault near Box Canyon. Further indications that the 1997 slip was not associated with rainfall include the following: (1) cracks formed not only in the mouth of Box Canyon, but also in 

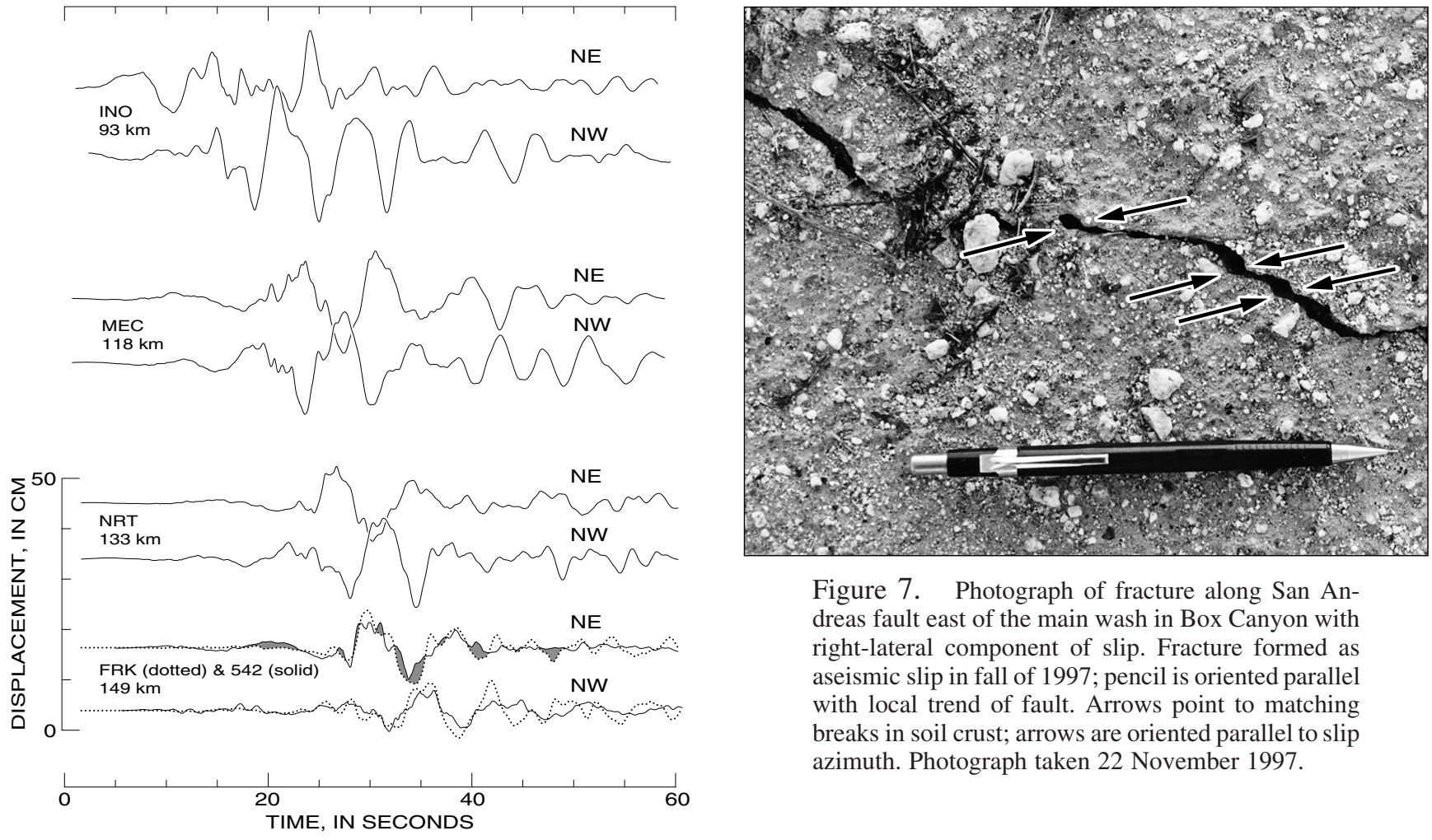

Figure 7. Photograph of fracture along San Andreas fault east of the main wash in Box Canyon with right-lateral component of slip. Fracture formed as aseismic slip in fall of 1997; pencil is oriented parallel with local trend of fault. Arrows point to matching breaks in soil crust; arrows are oriented parallel to slip azimuth. Photograph taken 22 November 1997.

Figure 6. Plot of strong motion records from the 1999 Hector Mine earthquake at stations Indio (INO), Mecca (MEC), North Shore (NRT), Frink (FRK), and station 542, located at Bombay Beach. All of these strong motion sites are located southwest of the San Andreas fault, except FRK, which is to the northeast. Station FRK is approximately the same distance from the 1999 Hector Mine epicenter as station 542 and is only $4 \mathrm{~km}$ from that other station. Plots shown are basically those of a time-distance series, except that plots for stations NRT and FRK-542 are moved apart for clarity. Plots shown are the northeast-southwest (NE) and northwest-southeast (NW) components of motion, normal and parallel to the 1999 Hector Mine waveform, respectively. Dark areas in the comparison of recordings from stations FRK and 542 mark periods of relative opening in a northeast-southwest direction between these stations.

hills composed of older alluvium to the east of the canyon; (2) the largest amount of slip occurred southeast of the wash; and (3) locally on slopes the right-lateral motion moved a canyon bottom uphill, which would not happen with a desiccation mechanism alone.

\section{Discussion}

Triggered slip in 1999 along the San Andreas fault in the southeastern Coachella Valley generally occurred where it had in previous moderate to large earthquakes. The four previous documented slip events, in 1968, 1979, 1986, and 1992, were triggered by earthquakes in various azimuthal directions away from the fault, and with varying magnitudes (see Fig. 1; Table 1). Likewise, slip that occurred in 1999

added to the range of source directions and magnitudes, although it was most similar to that of the 1992 Landers earthquake. Earlier slips, in general, formed along the fault in the Durmid Hill and Mecca Hills areas; two of the earlier events, 1986 and 1992, also triggered slip in the Indio Hills (Rymer, 2000, his Fig. 8, presents a more detailed description of earlier triggered slip events).

Gross similarities and differences between earlier triggered slip events and that in 1999 along the southern San Andreas fault are abundant. Of the documented triggered slip events, slip most commonly forms in the central Mecca Hills and occurs there in the most continuous stretches. Furthermore, the most pronounced slip occurs in the Mecca Hills regardless of the direction from the associated earthquake (Fig. 3), except in 1986, when slip was greatest in the Indio Hills (Williams et al., 1988). Two areas in the Mecca Hills where slip developed with relatively large amounts of displacement and more continuous stretches are between Thermal Canyon and Quarry Canyon and between Red Canyon and Painted Canyon (Figs. 2, 3). Also, in four of the events, 1968, 1979, 1992, and 1999, slip stopped, or started (depending on azimuth from source), within a few meters of the same spot near the mouth of Thermal Canyon. This topic was discussed by Sieh (1982) following the 1979 Imperial Valley earthquake, but by now there have been two additional events, in 1992 and 1999, that also had slip that probably initiated at the same location and then extended into areas commonly associated with triggered slip.

Timing of slip along the southern San Andreas fault in 1999 is constrained or inferred by a variety of observations. Field measurements and mapping of slip along the San An- 

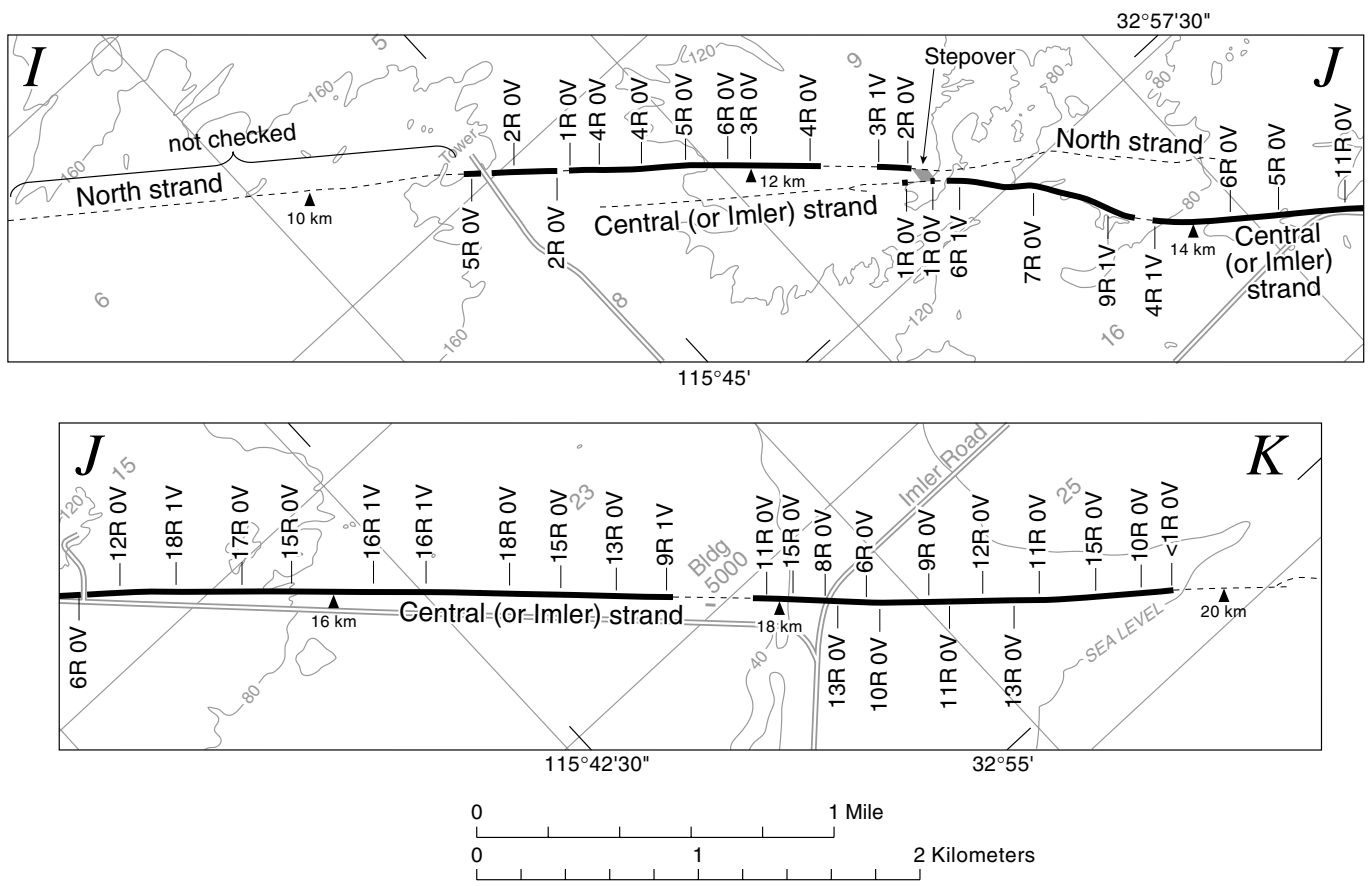

Figure 8. Strip maps of Superstition Hills fault with location of surface fractures formed in association with 1999 Hector Mine earthquake (see Fig. 1 for location of panels $I-J$ and $J-K)$. Dotted line, Superstition Hills fault; solid line, location of documented 1999 surface fractures. Slip values shown in millimeters for both right-lateral (R) and vertical (V) components. Vertical components of slip, where present, are indicated with either west (W) or east (E) side up. Map strips derived using selected contours from topographic maps. Distance scale along fault same as used by Sharp et al. (1986a, 1989); reference point located near western end of Superstition Hills fault.

dreas fault, as stated above, started the day of the Hector Mine earthquake. Following the 1992 Landers earthquake, Bodin et al. (1994) stated that slip developed along the southern San Andreas fault about 1 min after that mainshock, as the seismic wave passed through the area. We do not have creepmeter recordings for slip along the San Andreas fault in association with the Hector Mine earthquake; however, similar observations of fault effects associated in time with the passage of the seismic wave are recorded by Glowacka et al. (2002) for slip triggered by the Hector Mine earthquake near the southern end of the Imperial fault (discussed below under the Imperial fault). Also, the strong-motion records discussed above and shown in Figure 6 indicate that the seismic wave passed the areas of triggered slip from about 20 to $50 \mathrm{sec}$ after the Hector Mine mainshock.

Seismicity also was triggered in the Salton Trough by the 1999 Hector Mine earthquake (Gomberg et al., 2001; Glowacka et al., 2002; Hough and Kanamori, 2002). Hough and Kanamori (2002) conclude that the largest of the triggered events was an earthquake of $M 4.7$, which occurred beneath the Salton Sea, in the Brawley seismic zone (see hollow star in Figs. 1 and 5). Could this moderate event have triggered, or otherwise been causally associated with, the surface slip on the San Andreas fault? The event was large enough to be associated with surface slip in the Salton
Trough; for example, Brune and Allen (1967) reported a 1966 M 3.6 earthquake on the Imperial fault associated with about $10 \mathrm{~km}$ of discontinuous surface slip. Also, the timing of the small shock, about $30 \mathrm{sec}$ after the Hector Mine earthquake (Hough and Kanamori, 2002) fits within the 20-50sec timing of passage of the seismic wave as measured on the strong-motion records. However, the time-distance plot shown in Figure 6 indicates that the seismic wave and inferred transient pulse moved from north to south, from the general direction of the Hector Mine mainshock and toward the $M 4.7$ shock. Thus, we believe the surface slip in the Salton Trough was triggered by the Hector Mine mainshock.

The sum of slip in the Mecca Hills due to triggering in the past three decades is about $50 \mathrm{~mm}$, but this rate is slower than either the measured background creep rate (exclusive of triggered slip) or the geodetically determined rate. Louie et al. (1985) presented data showing a variable background creep rate along the southern San Andreas fault for the period 1967-1985. Their greatest creep rate, $3.1 \mathrm{~mm} / \mathrm{yr}$, was in the central Mecca Hills, the same area where triggered slip develops most readily and with relatively larger amounts of displacement. Geodetically determined broad-scale slip rates for the southernmost San Andreas fault zone using Global Positioning System (GPS) measurements and a rigid block model infer about $26 \pm 2 \mathrm{~mm} / \mathrm{yr}$ (Bennett et al., 
1996). This, of course, approaches 10 times larger than the even faster creep rates observed on the southern San Andreas fault during the past few decades. The difference between the combined triggered and creep rates and the broad-scale rates presumably will be released in a surface-rupturing earthquake.

\section{Superstition Hills Fault}

Field checks for surface breakage along the Superstition Hills fault began about 1 month after the Hector Mine earthquake. One of us (M.J.R.) checked the fault on 11 and 2223 November 1999. Cracks were mapped and slip was measured along about $9 \mathrm{~km}$ of the fault trace, representing distances from the Hector Mine epicenter to the northwest and southeast endpoints of observed triggered slip of about 188 and $196 \mathrm{~km}$, respectively (Table 1). The northwestern $11 \mathrm{~km}$ of the fault was not checked for surface slip due to logistical constraints, but cracks along the fault trace were observed extending farther to the northwest than our northwesternmost slip measurement. Thus, the northwestern extent of 1999 surface slip shown in Figures 8 and 9 is a minimum. Two other areas of the fault were not checked: (1) the area around Building 5000 (Fig. 8, panel J-K), due to a military exercise the week before our field measurements that had obliterated any cracks, and (2) the southeast end of the central strand, where freshly wind-blown sand covered any new fault breaks.

Surface slip in 1999 occurred on two of three structural fault segments associated with the 1987 Superstition Hills earthquake (Sharp et al., 1989). Superstition Hills fault segments are, from northwest to southeast, the north, central or Imler, and the Weinert strands. Fresh breaks associated with 1999 triggered slip were mapped along the southeastern end of the north strand and along most of the central or Imler strand. Spot checks were made along the Weinert strand, where no new surface slip was found. Surface breaks in 1999 formed in areas of uplifted Pleistocene lacustrine deposits.

Slip components were determined in the same manner as along the San Andreas fault, by measuring the displacement between matching irregularities in soil blocks or thin soil crusts along the local strike of the fault. We measured the slip vector, the azimuth of the slip, and the local strike of the fault; where present, the vertical component of slip and the direction of relative vertical displacement were also measured. Offset values were small, nowhere greater than $18 \mathrm{~mm}$ (Figs. 8, 9). Dextral slip was greatest near the southeastern end of the central or Imler strand (Figs. 8, 9). Locally, a small vertical component of slip was measured; nowhere did the vertical component exceed $1 \mathrm{~mm}$. Where a vertical component of slip was measured it was similar in relative proportions of slip and direction of slip relative to earlier episodes of triggered slip and the 1987 surface faulting.

\section{Discussion}

There were five episodes of documented triggered surface slip (1968, 1979, 1981, 1992, and 1999) and 1987 primary surface faulting (Sharp et al., 1989) on the Superstition Hills fault. The 1987 primary (coseismic) surface faulting was associated with an extended period of afterslip that initially occurred as more or less continuous slip and then decayed to episodic slip events (Bilham, 1989; Wennerberg and Sharp, 1997).

Timing of surface slip on the Superstition Hills fault in 1999 is directly constrained only by the dates of our field investigations. Field studies began about 1 months after the Hector Mine earthquake and, although surface fractures appeared fresh at the time of the field checks, other processes may have produced the cracks. Our field inspections of the San Andreas fault on the day of the Hector Mine earthquake and timing of slip along the southern Imperial fault as recorded in Mexicali Valley by Glowacka et al. (2002) indicate that a strong seismic wave from the Hector Mine earthquake passed through the Salton Trough. These observations provide no constraints on the timing of slip on the Superstition Hills fault, nor any proof that surface fractures there were necessarily associated with the Hector Mine earthquake. Rather, slip mapped along the Superstition Hills fault may have developed independently of the Hector Mine earthquake. For example, triggered slip along the Superstition Hills fault associated with the 1992 Landers earthquake was preceded by an episodic pulse of afterslip from the 1987 Superstition Hills earthquake (Bodin et al., 1994; R. V. Sharp, oral commun., 1992). Such a slip event may have occurred between the time of the Hector Mine earthquake and the first field inspections, or at some time shortly before the Hector Mine earthquake. Without further evidence on the timing of slip, we can only infer that slip mapped in 1999 was triggered by the Hector Mine earthquake. Closely bracketing dates of interferometric synthetic aperture radar (InSAR) scenes around the time of the Hector Mine earthquake may provide InSAR images that will aid in determining the timing of slip on the Superstition Hills fault and the total extent of the 1999 slip.

One of the most pronounced similarities between earlier triggered slip events and that in 1999 along the Superstition Hills fault is the location of surface breakage. In each event the fault has slipped at nearly the exact same place. Nail arrays and wooden-peg arrays placed across the Superstition Hills fault following the 1987 primary surface faulting were offset by the Hector Mine earthquake and in exactly the same place as in 1987 and in subsequent afterslip.

Another similarity between earlier slip events and that in 1999 is a propensity for the location of maximum displacement to be distributed away from the source of the earthquake, or oppositely skewed, as described by Allen $e t$ al. (1972) and Fuis (1982). Of the well-mapped triggered slip events along the Superstition Hills fault, in 1968, 1979, 

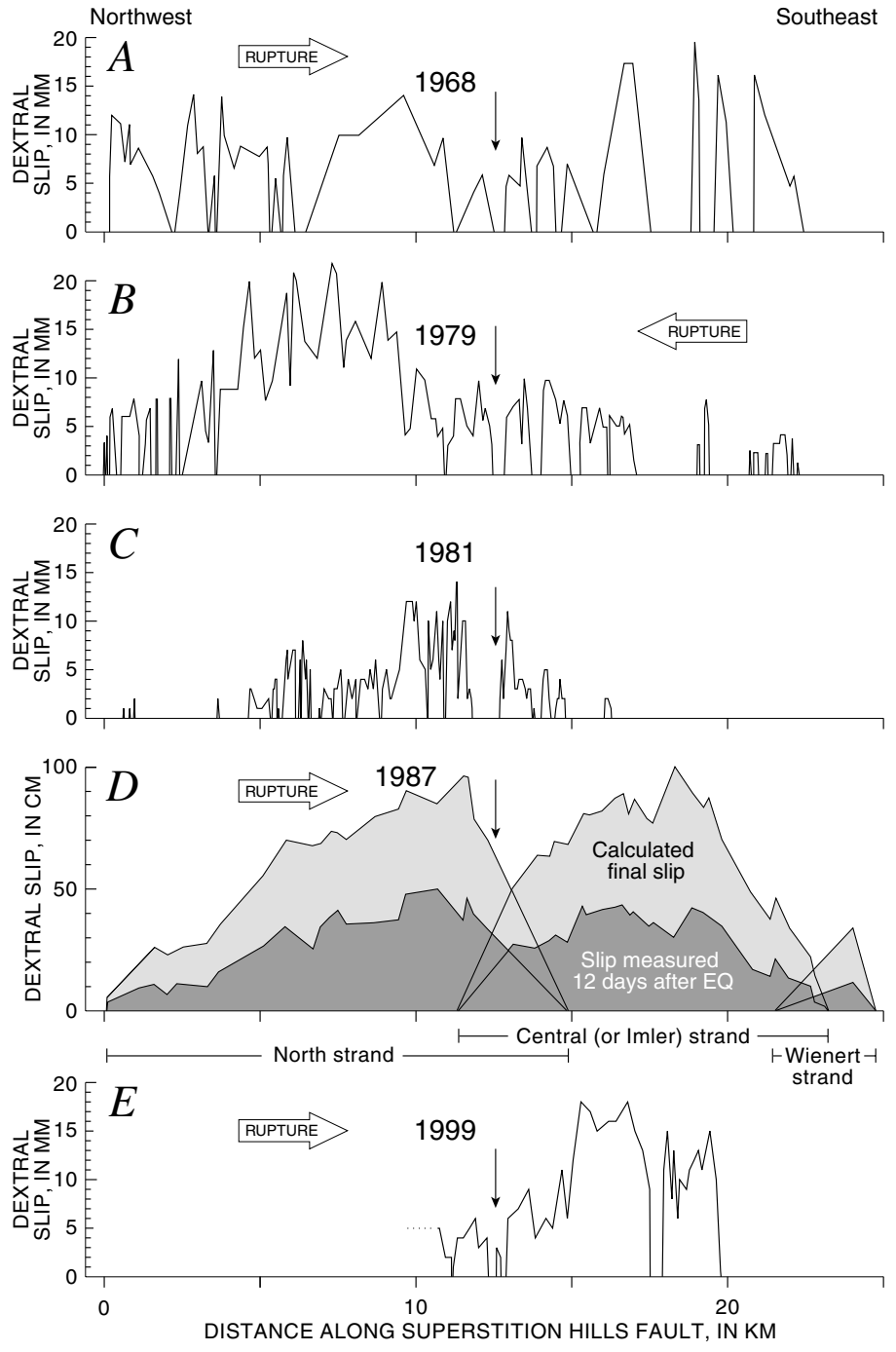

Figure 9. Right-lateral component of slip along Superstition Hills fault during primary surface faulting in 1987 and triggered slip in 1968, 1979, 1981, and 1999. A, 1968 triggered slip; $B, 1979$ triggered slip; $C, 1981$ triggered slip; $D$, surface faulting associated with the 1987 Superstition Hills earthquake; E, 1999 triggered slip. Detailed measurements were not made of surface slip in 1951 and 1992 and thus those events are not included in these plots. Distance scale along fault is relative to northwest end of faulting in 1987. A structural stepover between two fault strands as revealed in 1987 primary surface faulting is marked by thin vertical arrow. Same distance and slip scales as Figs. 3 and 11. Wide horizontal arrow marks direction of rupture for individual earthquakes; seismic waves from the 1981 Westmorland earthquake arrived approximately normal to the Superstition Hills fault and thus no rupture direction is shown for that event. Slip measured on creepmeters not included in these plots.
1981, and 1999, slip was oppositely skewed in three of the four events (the exception being 1981). The 1981 Westmorland earthquake was located such that seismic waves and static stress changes arrived approximately normal, about $87^{\circ}$, to the Superstition Hills fault. Interestingly, the 1987 primary tectonic surface faulting did not show this skewed nature of slip distribution, neither in initial slip nor in projected final slip (Fig. 9D).

Mapping the 1999 triggered slip was an opportunity to carefully measure the distribution and amount of surface slip within the area of a structural stepover in the main trace of the Superstition Hills fault, as was revealed by the 1987 surface rupture (Sharp et al., 1989; Rymer, 1989). As with earlier episodes of triggered slip, the 1999 surface breakage extended through the 50-m-wide (erroneously stated as 100m-wide by Rymer, 1989) structural stepover (see Fig. 8, I$J$ ). Detailed measurements of the 1999 triggered slip in the stepover area show a decrease in slip on both north and central strands as one approaches the stepover and only very minor (1-2 mm) dextral slip on individual strands extending past where slip is transferred from one strand to the other (Figs. 8, 9E) (Rymer, 1989). Also, the 1999 triggered slip apparently was transferred from one fault strand to the other, where Rymer speculated that most of the 1987 primary slip was partitioned through the stepover (gray area in Fig. 8, panel $I-J$; vertical arrow in Fig. 9).

\section{Imperial Fault}

Our study of the Imperial fault is restricted to that within the Imperial Valley, north of the U.S.-Mexico border (Fig. 1). Glowacka et al. (2002) discuss instrumental measurements of triggered creep, tilt, and seismicity associated with the 1999 Hector Mine earthquake near the southern end of the Imperial fault, in the Mexicali Valley.

Field checks for surface breakage along the Imperial fault began 25 days after the Hector Mine earthquake. One of us (M.J.R.) checked the Imperial fault on 10 and 23 November 1999 . Field checks were made primarily along roadways and dirt shoulders that cross the fault; locally, where 
the fault lies in uncultivated fields, mapping and measurements were made while walking along the fault trace.

Discontinuous surface breaks formed along the Imperial fault over a distance of about $22 \mathrm{~km}$ (Figs. 10, 11; Table 1), representing distances from the Hector Mine epicenter to the northwest and southeast endpoints of the triggered slip of about 204 and $226 \mathrm{~km}$, respectively (Table 1). Two factors limited the continuity and extent of our mapping surface breakage. Cultivated fields, especially fields with a dense growth of crops, were not checked for surface fractures. Locally, fields that recently had been cleared of crops were checked for surface breaks, but this generally was futile because of abundant tire tracks and general disruption of the ground surface. Another area of ground disruption was north of Harris Road (Fig. 10, $L-M$ ). There, surface breaks clearly extended farther north than our northernmost slip measurements, but ongoing construction and modification of drainage canals obliterated evidence of the breaks. We believe the 1999 triggered slip extended farther north, because our northernmost measurement (10 mm dextral slip) was rather large and there was no indication of slip decay as near the end of a rupture. No slip was observed at Keystone Road and, thus, the full northern extent of 1999 triggered slip lay somewhere between Harris and Keystone Roads, at an unknown distance north of our measurement sites.

Slip components were determined in the same manner as along the San Andreas fault, by measuring the displacement between matching irregularities in soil blocks or thin soil crusts along the local strike of the fault. We measured the slip vector, the azimuth of the slip, and the local strike of the fault; where present, the vertical component of slip and the direction of relative vertical displacement were also measured. Offset values were small, nowhere greater than $19 \mathrm{~mm}$ (Figs. 10, 11). Dextral slip was greatest near the middle of triggered surface breakage (Figs. 10,11). Locally there was a minor ( 1-3 mm) vertical component of slip; larger proportions of vertical slip (up to $10 \mathrm{~mm}$ ) occurred in Mesquite basin (near kilometers 23-25, Fig. 10), where fault scarps indicate a long-term oblique slip for this part of the Imperial fault.

\section{Discussion}

The Imperial fault has a rich history of documented surface slips. Primary surface faulting was associated with moderate to large earthquakes in 1940 (M 7.1) and 1979 (M 6.4); small earthquakes in 1966 ( $M$ 3.6) and 1975 ( $M$ 4.2); triggered slip occurred in 1968, 1981, 1987, and 1999; and there have been many earthquake swarms and minor aseismic creep events along the fault (Goulty et al., 1978; Louie et al., 1985; Cohn et al., 1982; Sharp, 1989). Afterslip associated with the 1979 earthquake continued episodically for years after that event (Sharp et al., 1982). Furthermore, Allen et al. (1972) stated that an earthquake on the Superstition Hills fault in 1971 also triggered slip along the Imperial fault.
Timing of slip on the Imperial fault within the Imperial Valley is directly constrained only by the time of field investigations; however, Glowacka et al. (2002) instrumentally recorded triggered slip and tilt along the southern end of the Imperial fault, in the Mexicali Valley. They state that effects of the Hector Mine earthquake reached the southern Imperial fault about $1.5 \mathrm{~min}$ after the mainshock, as the seismic wave passed through the area. The freshness of breaks seen on the Imperial fault in the Imperial Valley combined with the data of Glowacka et al. (2002) lead us to believe that the surface breaks were triggered by the 1999 Hector Mine earthquake.

As with the San Andreas and Superstition Hills faults, the location of surface breakage in 1999 along individual traces of the Imperial fault closely matched the location of earlier triggered slip and primary surface rupture. Fresh surface breaks, where they occurred, formed in exactly the same place as previous slips; variations of location of breakage from one event to another vary by only a few centimeters, at most.

A comparison of the distribution and amount of the few well-mapped slips along the Imperial fault indicates a rather random distribution (Fig. 11), unlike slips along the San Andreas and Superstition Hills faults. Primary surface ruptures in 1940 and 1979 are similar, in both distribution and amount of slip, from kilometer 7 to the northern end of the fault (Fig. 11; Sharp, 1982). Farther south of kilometer 7, near the U.S.-Mexico border, the 1940 break attained displacements of up to $6 \mathrm{~m}$ (Sharp, 1982). In contrast, triggered slip in 1981, 1987, and 1999 occurred in different locations (though with some commonality) and attained maximum slip at different locations. In spite of these differences, there are two important points in common. First, for each of the triggered slips, surface breakage was discontinuous. Even with densely vegetated fields that obscure minor surface breaks, enough measurements were made within roadways and barren fields to prove that locally no slip occurred. For the 1999 triggered slip, negative evidence of slip is shown with a black dot along the origin (Fig. 11). Second, discrete zones along the Imperial fault commonly are maintained through time with little or no slip; this is true for both triggered slip events and primary tectonic rupture events (Fig. 11). Figure 11 shows four shaded zones, marked $w, x, y$, and $z$, where complexity exists in the surface trace of the Imperial fault, as became apparent following the 1979 surface rupture (Sharp et al., 1982). Zone $w$ is a dilational jog in the trace of the fault. There, the ground surface is clear of vegetation and has a thin soil crust, in which surface breaks are easily detected and measured. In all five of the slip events plotted in Figure 11, very little or no slip was detected here. Zones $x$ and $z$ are areas where multiple strands add complexity to the Imperial fault (compare Figs. 10 and 11). As with zone $w$, these two zones commonly (except zone $z$ in 1979) show little to no slip (Fig. 11). Zone $y$ has, with minor exceptions, shown little to no slip; zone $y$ is where the Brawley fault zone interacts, or may connect, with the Imperial fault. 

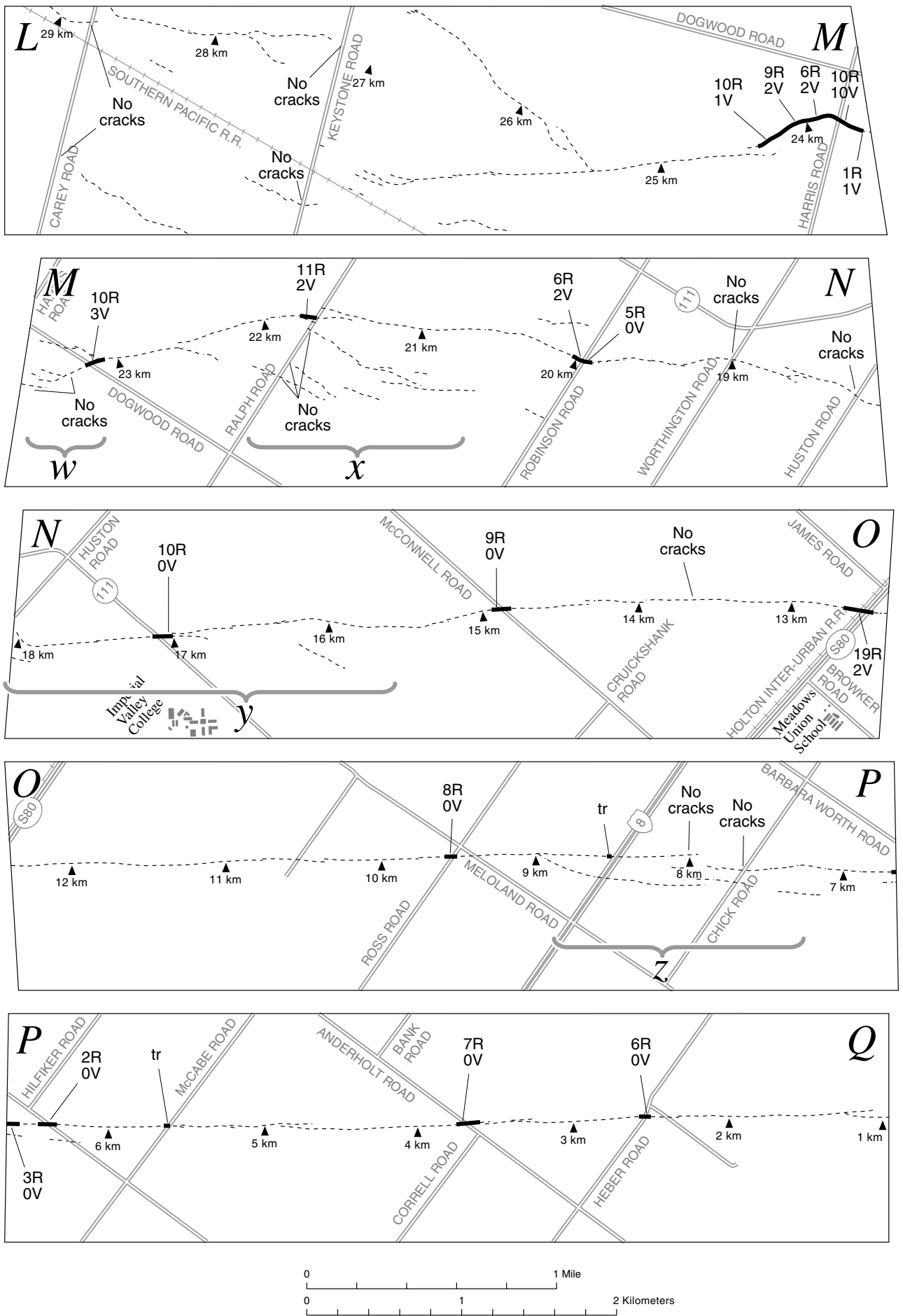

Figure 10. Strip maps of Imperial fault with location of surface fractures formed in association with 1999 Hector Mine earthquake (see Fig. 1 for location of panels $L-$ $Q)$. Dotted line, Imperial fault; solid line, location of documented 1999 surface fractures. Slip values shown in millimeters for both right-lateral (R) and vertical (V) components. Vertical components of slip, where present, are indicated with either west (W) or east (E) side up. Map strips derived using selected contours from topographic maps; location of strips shown in Fig. 1. Distance scale along fault same as used by Sharp et al. (1982); reference point located near southern end of Imperial fault. 


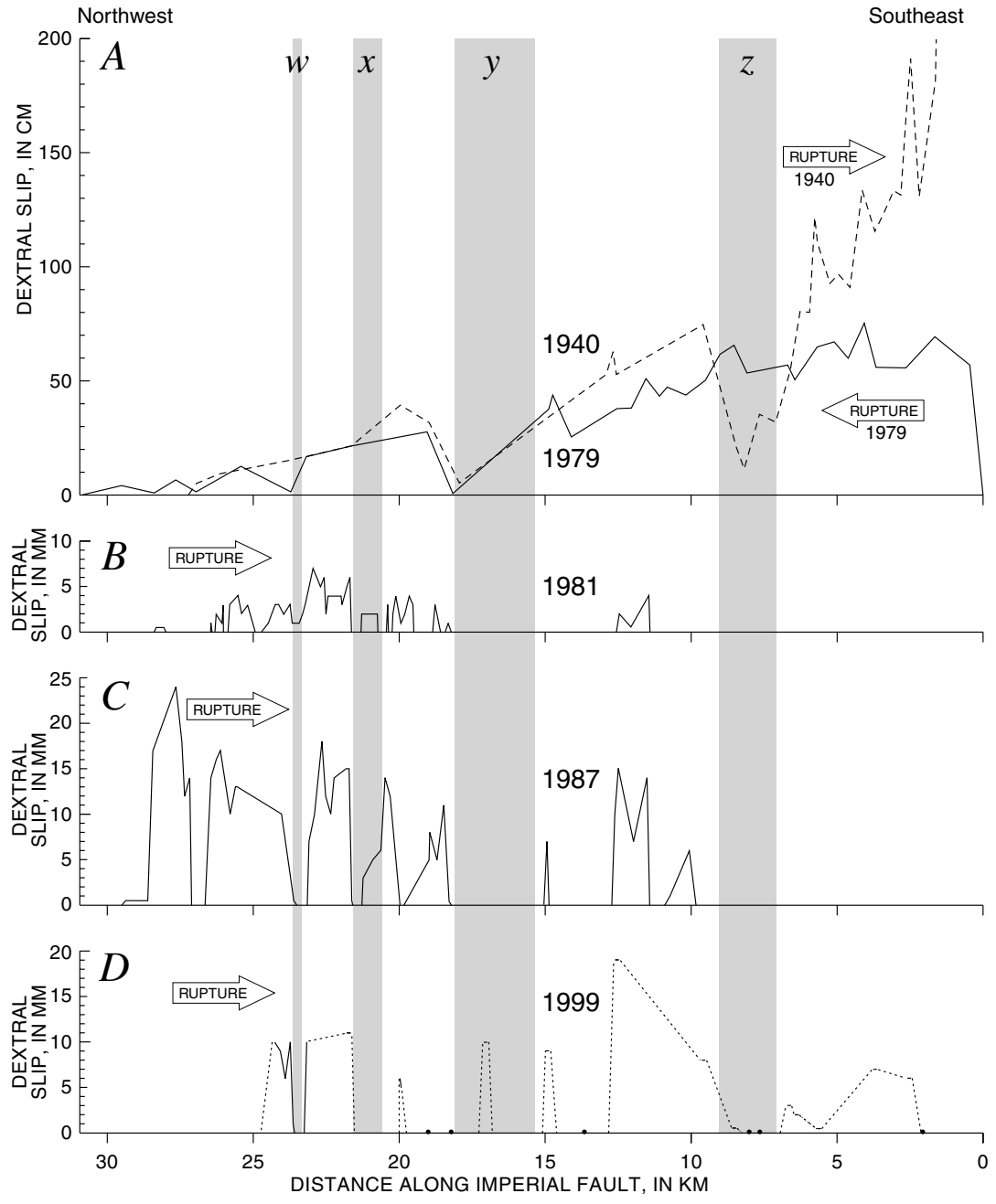

Figure 11. Right-lateral component of slip along northern Imperial fault during two periods of primary surface faulting and three triggered slips. A, 1940 and 1979 primary surface faulting; $B$, triggered slip associated with the 1981 Westmorland earthquake; $C$, triggered slip associated with the 1987 Superstition Hills earthquake; $D$, triggered slip associated with the 1999 Hector Mine earthquake. Distance scale along faults is relative to south end of faulting in 1979. Detailed measures were not made of surface slips in 1966 and 1968 and thus those episodes are not included in these plots. Slip shown in $A$ for the 1940 earthquake includes only that along northern part of Imperial fault; surface slip in 1940 extended approximately $30 \mathrm{~km}$ farther to the south and displacement reached a maximum of about $6 \mathrm{~m}$ right-lateral slip near the U.S.-Mexico border (Sharp, 1982). Short stretches of the Imperial fault with rupture complexity in the 1979 earthquake are marked as gray zones $w, x$, and $z$. Low slip values or no slip is characterized for each of these stretches. Another stretch of fault with low slip in each of the events is found from about 15 to $18 \mathrm{~km}$ (zone $y$ ), where the Brawley fault zone structurally interacts with the Imperial fault. Same distance and slip scales as Figs. 3 and 9. Wide horizontal arrow marks direction of rupture for individual earthquakes.

\section{Other Faults}

The 1999 Hector Mine earthquake may have triggered surface slip on faults in the Salton Trough region other than the San Andreas, Superstition Hills, and Imperial faults. However, field checks along four faults, two of which have moved in the recent past, showed no evidence of additional surface slip. Faults investigated are the Skeleton Canyon and Painted Canyon faults in the Mecca Hills area of the San Andreas fault zone; the Brawley fault zone, northeast of the Imperial fault; and the Coyote Creek fault, part of the San Jacinto fault zone, northwest of the Superstition Hills fault. The Skeleton Canyon and Painted Canyon faults were checked only in Box Canyon and Painted Canyon. In contrast, we carefully searched for new surface slip along the Brawley fault zone, which ruptured in the 1979 Imperial Valley earthquake (Sharp et al., 1982). We searched along Keystone, Harris, and Worthington road crossings of the Brawley fault zone; road pavement, dirt shoulders, and concrete canal liners were checked. No fresh breaks were observed. The Coyote Creek fault was checked by Geoff Faneros (San Diego State Univ., oral commun., 1999) for new surface slip at only one place, near the southeastern end of the Ocotillo Badlands. This was the site of afterslip and triggered slip from other earthquakes in the region (Burford, 1972; Hudnut and Clark, 1989). No new slip was observed in association with the 1999 Hector Mine earthquake; however, surface slip may have occurred elsewhere along the fault.

\section{Discussion and Conclusions}

Some questions as to the nature of triggered slip in the Salton Trough now can be answered in light of new data presented in this paper. Field evidence indicates a transient opening as the Hector Mine seismic waves passed the southern San Andreas fault (Fig. 4). That observation is supported by strong-motion records presented herein, showing relative opening between strong-motion stations on opposite sides of the fault at the time of seismic wave passage (Fig. 6). Bodin et al. (1994) also proposed a model for slip at the time of the passage of the seismic waves; however, their proposed model incorporates transient increased pore pressures during fault-normal contraction and reduction of effective normal 
stress across the fault. We believe our direct observations best support the transient-opening model of fault slip.

An intriguing result of our measurements and compilations of repeated earlier slips is that each of the faults in the Salton Trough with 1999 triggered slip behaves differently. That is, comparison of triggered slips on the San Andreas fault show the most frequent and largest amounts of slip in the central Mecca Hills (Fig. 3), regardless of distance, rupture direction, or magnitude of the causative earthquake. For the Superstition Hills fault, distance and magnitude likewise show little effect, but rupture direction characteristically produces slip distributions skewed away from the source (Fig. 9). The Imperial fault, in further contrast to the two other faults, shows a more random distribution of triggered slip (Fig. 11).

Theoretical and laboratory models suggest plausible explanations of variations in behavior of triggered slip on faults in the Salton Trough. Models by Hartzell and Archuleta (1979), Heaton (1990), Brune et al. (1993), Andrews and Ben-Zion (1997), Harris and Day (1997), Ben-Zion and Andrews (1998), Anooshehpoor and Brune (1999), Ranjith and Rice (2001), and Gerde and Marder (2001), among others, indicate a transient opening as a mechanism of slip along a fault and a dependence on velocity contrasts or a lowvelocity fault zone. Variations in thickness of fault gouge in some of these models dictates the distribution of slip, especially if the fault is along the margins of the gouge or lowvelocity fault zone. A thick zone of gouge, or in the case of the San Andreas fault in the Mecca Hills, a thick zone of mudstone injected into the fault (see Rymer, 1994), may aid development of slip. The presence of a low-velocity zone provides material contrast and aids in a self-sustained propagation of the slip pulse (Andrews and Ben-Zion, 1997; Harris and Day, 1997).

Oppositely skewed triggered slip on the Superstition Hills fault following the 1968 and 1979 slip events was observed and discussed by Allen et al. (1972) and Fuis (1982). Fuis (1982) proposed two possible explanations for slip skewed away from the source: (1) slip is complementary to earlier slip, or (2) slip adjustments were triggered in a stress field that varied oppositely along the fault. We favor a rupture-runaway explanation, also discussed by Fuis (1982), which is further supported by laboratory and theoretical studies. These studies indicate that on coherent breaks (with no structural complications), displacement is skewed in a direction away from the point of initiation. In such models, slip is skewed away from the source due to focusing of stress during rupture propagation (Hartzell and Archuleta, 1979; Archuleta and Day, 1980). Additional studies presented by Heaton (1990) and Brune et al. (1993) further speculated that rupture runaway, producing oppositely skewed slip may develop along faults. Slip triggered along the Superstition Hills fault by the 1999 Hector Mine earthquake likewise is skewed away from the source (Fig. 9E) and thus adds to the history of oppositely skewed slip on the fault. The Superstition Hills fault clearly contains a structural complication in the stepover between the north and Imler strands (Rymer, 1989) (Figs. 8, 9) that at first glance may challenge the condition of coherent breaks; however, even though there is less surface fault slip in the structural stepover (see Rymer, 1989, and brief discussion below), clearly the stepover has not impeded propagation of slip through this structural complexity in at least five periods of surface fault slip, both triggered and primary tectonic slip (Fig. 9).

Another point that comes into clearer focus with our data is the decrease of slip in areas of structural stepovers and multiple fault strands. This is not a new idea, but one that is more apparent now that we have multiple surface slips along individual faults. We now have well-mapped slip distributions along the southern San Andreas, Superstition Hills, and Imperial faults during five events for each of these faults (Figs. 3, 9, 11). The structural stepover on the Superstition Hills fault consistently has shown low slip values (Sharp et al., 1989; Rymer, 1989) (Fig. 9), even after summing slip on minor faults between and around the stepover (Rymer, 1989). Likewise, smaller structural complexities in the surface trace of the Imperial fault, as revealed in the 1979 surface rupture (Sharp et al., 1982), show less slip during both primary rupture and remotely triggered slip (Fig. 11, zones $w$ to $z$ ). We speculate that instead of having future slip compensate for past low-slip zones, the areas of structural complexity include off-fault deformation (folding, rotation, and other nonbrittle deformation) that will not be included in surface displacement.

The location and shape of the Salton Trough may add further structural controls on the location and likelihood of triggered slip. Figure 5 shows the location of triggered slip in 1999 and the subsurface margins of the Salton Trough (heavy gray line). Field (1996) presented data and a model for spectral amplification and clear basin-edge-induced waves associated with the 1992 Landers earthquake. His study was located approximately halfway between Palm Springs and Indio. A casual look at the shape of the trough and the source of the Hector Mine mainshock indicates that 1999 seismic waves likewise may be associated with basinedge effects. While this may be the case for the San Andreas fault in association with the Hector Mine earthquake, however, such is not the case for the other two faults with triggered slip: the Superstition Hills fault on the opposite side of the basin and the Imperial fault lying within the basin. Furthermore, given the location and direction of seismic waves from each of the causative earthquakes for slip along the San Andreas, Superstition Hills, and Imperial faults (Table 1; see black stars in Figs. 1, 5), clearly basin edge effects are not a controlling factor for development of triggered slip.

These and other speculations on the relations of slip, material properties, and structural control should be pursued by further comparison of real geologic properties and theoretical and laboratory models. The Salton Trough is a natural lab for such comparisons, with its multiple repeats of triggered slip, aseismic slip (creep), and, in the case of the Coyote Creek (not included in this report), Superstition Hills, 
and Imperial faults, primary tectonic slip. We agree with the suggestions of Bodin et al. (1994) for a strain-monitoring array to help resolve the causative mechanism of triggered slip. We further suggest installation of two overlapping creepmeters, set approximately $45^{\circ}$ to a fault and set normal to each other. Such an installation could further resolve the development and nature of a future transient pulse along the San Andreas fault. A third suggestion is the use of InSAR data to better understand the distribution and amount of slip around structural complexities, such as the stepover in the central Superstition Hills fault. The bare ground and gentle slopes in that area, combined with repeated surface slips and aseismic creep events, make this an ideal place to test some of our hypotheses.

\section{Acknowledgments}

We thank S. Myers (Cathedral City) for field assistance in this study. Conversations with USGS colleagues L.M. Jones, K.W. Hudnut, and M.J.S. Johnston aided the investigation of 1997 aseismic creep. Geoff Faneros (San Diego State Univ.) kindly checked the Coyote Creek fault for triggered slip. K.W. Hudnut, V.E. Langenheim, and H.D. Stenner provided extremely helpful reviews of an earlier version of the manuscript.

\section{References}

Allen, C. R., M. Wyss, J. N. Brune, A. Grantz, and R. E. Wallace (1972). Displacement on the Imperial, Superstition Hills, and San Andreas faults triggered by the Borrego Mountain earthquake, in The Borrego Mountain Earthquake, U.S. Geol. Surv. Profess. Pap. 787, 87-104.

Andrews, D. J., and Y. Ben-Zion (1997). Wrinkle-like slip pulse on a fault between different materials, J. Geophys. Res. 102, 553-571.

Anooshehpoor, A., and J. N. Brune (1999). Wrinkle-like Weertman pulse at the interface between two blocks of foam rubber with different velocities, Geophys. Res. Lett. 26, 2025-2028.

Archuleta, R. J., and S. M. Day (1980). Dynamic rupture in a layered medium: the 1966 Parkfield earthquake, Bull. Seism. Soc. Am. 70, 671-689.

Bennett, R. A., W. Rodi, and R. E. Reilinger (1996). Global positioning system constraints on fault slip rates in southern California and northern Baja, Mexico, J. Geophys. Res. 101, 21,943-21,960.

Ben-Zion, Y., and D. J. Andrews (1998). Properties and implications of dynamic rupture along a material interface, Bull. Seism. Soc. Am. 88, 1085-1094.

Bilham, R. (1989). Surface slip subsequent to the 24 November 1987 Superstition Hills, California, earthquake monitored by digital creepmeters, Bull. Seism. Soc. Am. 79, 424-450.

Bilham, R., and P. Williams (1985). Sawtooth segmentation and deformation processes on the southern San Andreas fault, California, Geophys. Res. Lett. 12, 557-560.

Bodin, P., R. Bilham, J. Behr, J. Gomberg, and K. W. Hudnut (1994). Slip triggered on southern California faults by the 1992 Joshua Tree, Landers, and Big Bear earthquakes, Bull. Seism. Soc. Am. 84, 806-816.

Brune, J. N., and C. R. Allen (1967). A low-stress-drop, low-magnitude earthquake with surface faulting: the Imperial, California, earthquake of March 4, 1966, Bull. Seism. Soc. Am. 57, 501-514.

Brune, J. N., S. Brown, and P. A. Johnson (1993). Rupture mechanism and interface separation in foam rubber models of earthquakes: a possible solution to the heat flow paradox and the paradox of large overthrusts, Tectonophysics 218, 59-67.

Burford, R. O. (1972). Continued slip on the Coyote Creek fault after the Borrego Mountain earthquake, in The Borrego Mountain Earthquake, U.S. Geol. Surv. Profess. Pap. 787, 105-111.
Clark, M. M. (1984). Map showing recently active breaks along the San Andreas fault and associated faults between Salton Sea and Whitewater River-Mission Creek, California, U.S. Geol. Surv. Misc. Inv. Map I-1483, scale 1:24,000.

Cohn, S. N., C. R. Allen, R. Gilman, and N. R. Goulty (1982). Preearthquake and postearthquake creep on the Imperial fault and the Brawley fault zone, in The Imperial Valley, California, Earthquake of October 15, 1979, U.S. Geol. Surv. Profess. Pap. 1254, 161-167.

Field, E. H. (1996). Spectral amplification in a sediment-filled valley exhibiting clear basin-edge-induced waves, Bull. Seism. Soc. Am. 86, 991-1005.

Fuis, G. S. (1982). Displacement on the Superstition Hills fault triggered by the earthquake, in The Imperial Valley, California, Earthquake of October 15, 1979, U.S. Geol. Surv. Profess. Pap. 1254, 145-154.

Fuis, G. S., W. D. Mooney, J. H. Healey, G. A. McMechan, and W. J. Lutter (1982). Crustal structure of the Imperial Valley region, in The Imperial Valley, California, Earthquake of October 15, 1979, U.S. Geol. Surv. Profess. Pap. 1254, 25-49.

Gerde, E., and M. Marder (2001). Friction and fracture, Nature 413, 285288.

Glowacka, E., F. A. Nava, G. Díaz de Cossío, V. Wong, and F. Farfán (2002). Fault slip, seismicity, and deformation in Mexicali Valley, Baja California, Mexico, after the M 7.1 1999 Hector Mine earthquake, Bull. Seism. Soc. Am. 92, 1290-1299 (this issue).

Gomberg, J., P. A. Reasenberg, P. Bodin, and R. A. Harris (2001). Earthquake triggering by seismic waves following the Landers and Hector Mine earthquakes, Nature 411, 462-466.

Goulty, N. R., R. O. Burford, C. R. Allen, R. Gilman, C. E. Johnson, and R. P. Keller (1978). Large creep events on the Imperial fault, California, Bull. Seism. Soc. Am. 68, 517-521.

Harris, R. A., and S. M. Day (1997). Effects of a low-velocity zone on a dynamic rupture, Bull. Seism. Soc. Am. 87, 1267-1280.

Hartzell, S. H., and R. J. Archuleta (1979). Rupture propagation and focusing of energy in a foam rubber model of a stick slip earthquake, J. Geophys. Res. 84, 3623-3636.

Heaton, T. H. (1990). Evidence for and implications of self-healing pulses of slip in earthquake rupture, Phys. Earth Planet. Inter. 64, 1-20.

Hough, S., and H. Kanamori (2002). Source properties of earthquakes near the Salton Sea triggered by the 16 October 1999 M 7.1 Hector Mine, California, earthquake, Bull. Seism. Soc. Am. 92, 1281-1289 (this issue).

Hudnut, K. W., and M. M. Clark (1989). New slip along parts of the 1968 Coyote Creek fault rupture, California, Bull. Seism. Soc. Am. 79, 451465.

Jennings, C. W. (Compiler) (1994). Fault activity map of California and adjacent areas, California Department of Conservation, Division of Mines and Geology, Geologic Data Map Series No. 6, scale $1: 750,000$

Louie, J. N., C. R. Allen, D. C. Johnson, P. C. Haase, and S. N. Cohn (1985). Fault slip in southern California, Bull. Seism. Soc. Am. 75, 811-833.

McGill, S. F., C. R. Allen, K. W. Hudnut, D. C. Johnson, W. F. Miller, and K. E. Sieh (1989). Slip on the Superstition Hills fault and on nearby faults associated with the 24 November 1987 Elmore Ranch and Superstition Hills earthquakes, southern California, Bull. Seism. Soc. Am. 79, 362-375.

Ranjith, K., and J. R. Rice (2001). Slip dynamics at an interface between dissimilar materials, J. Mech. Phys. Solids 49, 341-361.

Rymer, M. J. (1989). Surface rupture in a fault stepover on the Superstition Hills fault, California, in Fault Segmentation and Controls of Rupture Initiation and Termination D. P. Schwartz and R. H. Sibson (Editors) U.S. Geol. Surv. Open-File Rept. 89-315, 309-323.

Rymer, M. J. (1994). Quaternary fault-normal thrusting in the northwestern Mecca Hills, southern California, in Geological Investigations of an Active Margin: Guidebook, 1994, S. F. McGill and T. M. Ross (Editors) Geol. Soc. Am., Cordilleran Sect., San Bernardino County Museum, Redlands, California, 325-329. 
Rymer, M. J. (2000). Triggered surface slips in the Coachella Valley area associated with the 1992 Joshua Tree and Landers, California, earthquakes, Bull. Seism. Soc. Am. 90, 832-848.

Saltus, R. W., and R. C. Jachens (1995). Gravity and basin-depth maps of the Basin and Range province, western United States, U.S. Geol. Surv. Geophys. Inv. Map GP-1012, scale 1:2,500,000.

Sharp, R. V. (1982). Comparison of 1979 surface faulting with earlier displacements in the central Imperial Valley, in The Imperial Valley, California, Earthquake of October 15, 1979, U.S. Geol. Surv. Profess. Pap. 1254, 213-221.

Sharp, R. V. (1989). Pre-earthquake displacement and triggered displacement on the Imperial fault associated with the Superstition Hills earthquake of 24 November 1987, Bull. Seism. Soc. Am. 79, 466-479.

Sharp, R. V., J. J. Lienkaemper, M. G. Bonilla, D. B. Burke, B. F. Cox, D. G. Herd, D. M. Miller, D. M. Morton, D. J. Ponti, M. J. Rymer, J. C. Tinsley, and J. C. Yount (1982). Surface faulting in the central Imperial Valley, in The Imperial Valley, California, Earthquake of October 15, 1979, U.S. Geol. Surv. Profess. Paper 1254, 119-114.

Sharp, R. V., M. J. Rymer, and J. J. Lienkaemper (1986a). Surface displacements on the Imperial and Superstition Hills faults triggered by the Westmorland, California, earthquake of 26 April 1981, Bull. Seism. Soc. Am. 76, 949-965.

Sharp, R. V., M. J. Rymer, and D. M. Morton (1986b). Trace-fractures on the Banning fault created in association with the 1986 North Palm Springs earthquake, Bull. Seism. Soc. Am. 76, 1838-1843.

Sharp, R. V., K. E. Budding, J. Boatwright, M. J. Ader, M. G. Bonilla, M. M. Clark, T. E. Fumal, K. K. Harms, J. J. Lienkaemper, D. M. Morton, B. J. O’Neill, C. L. Ostergren, D. J. Ponti, M. J. Rymer, J. L. Saxton, and J. D. Sims (1989). Surface faulting along the Superstition Hills fault and nearby faults associated with the earthquakes of 24 November 1987, Bull. Seism. Soc. Am. 79, 252-281.

Shifflett, H., and R. Witbaard (1996). Multiple precursors to the Landers earthquake, Bull. Seism. Soc. Am. 86, 113-121.

Sieh, K. E. (1982). Slip along the San Andreas associated with the earthquake, in The Imperial Valley, California, Earthquake of October 15, 1979, U.S. Geol. Surv. Profess. Pap. 1254, 155-160.
Sieh, K. E., and P. L. Williams (1990). Behavior of the southernmost San Andreas fault during the past 330 years, J. Geophys. Res. 95, 66296645.

Treiman, J. A., K. J. Kendrick, W. A. Bryant, T. K. Rockwell, and S. F. McGill (2002). Primary surface rupture associated with the $M_{\mathrm{w}} 7.1$ 16 October, 1999 Hector Mine earthquake, San Bernardino County, California, Bull. Seism. Soc. Am. 92, 1171-1191 (this issue).

Wennerberg, L. G., and R. V. Sharp (1997). Bulk-friction modeling of afterslip and the modified Omori law, Tectonophysics 277, 109-136.

Williams, P. L., and K. E. Sieh (1987). Slow regular slip along the southernmost San Andreas fault for the past 40, 80, and 300 years (abstract), EOS, Trans. Am. Geophys. Union 68, 1506.

Williams, P. L., S. F. McGill, K. E. Sieh, C. R. Allen, and J. N. Louie (1988). Triggered slip along the San Andreas fault after the 8 July 1986 North Palm Springs earthquake, Bull. Seism. Soc. Am. 78, 1112 1122.

U.S. Geological Survey

345 Middlefield Road, MS 977

Menlo Park, California 94025

(J.B., M.J.R., L.C.S.)

Department of Geological Sciences

California State University

Northridge, California 91330

(J.D.Y.)

Seismological Laboratory

California Institute of Technology

Pasadena, California 91125

(J.L.)

Manuscript received 31 January 2001. 